\title{
Pelaksanaan Keselamatan dan Kesehatan Kerja Gangguan Muskoloskeletal Akibat Pekerjaan Pada Perawat
}

\author{
Natasia Atania Sitepu
}

natasiaatania2@gmail.com

\section{Latar Belakang}

Rumah Sakit merupakan tempat kerja serta tempat berkumpulnya orang-orang sehat (petugas dan pengunjung) dan orang-orang sakit (pasien) sehingga rumah sakit merupakan tempat kerja yang mempunyai risiko tinggi terhadap penyakit akibat kerja maupun penyakit akibat kecelakaan kerja. Salah satu komponen pelayanan kesehatan di rumah sakit adalah perawat. Peran perawat sangat penting untuk sebuah pelayanan rumah sakit karena tanpa mereka pelayanan rumah sakit menjadi buruk. Perawat sebagai tenaga pelayanan kesehatan berinteraksi langsung dengan pasien dengan intensitas yang paling tinggi dibandingkan dengan komponen yang lainnya.

Perilaku kesehatan dan keselamatan kerja perawat di rumah sakit sangat penting, karena tindakan perawat sekecil apapun dapat menimbulkan risiko terhadap perawat dan pasien. Kecelakaan kerja merupakan kejadian yang tidak terjadi secara kebetulan, melainkan ada sebabnya. Oleh karena ada penyebabnya, sebab kecelakaan harus diteliti dan ditemukan, agar untuk selanjutnya dengan tindakan korektif yang ditujukan kepada penyebab itu serta dengan upaya preventif lebih lanjut kecelakaan dapat dicegah dan kecelakaan serupa tidak berulang kembali (Suma'mur, 2013).

Contoh bahaya potensial bagi pekerja termasuk paparan terhadap agen infeksius, kimiawi, dan fisik (nuklir, energi elektromagnetik, kebisingan); tugas berat dan tugas berulang; terpeleset, tersandung, dan jatuh; menekankan; kekerasan di tempat kerja; dan risiko yang terkait dengan organisasi kerja yang kurang optimal. Ini dapat menyebabkan infeksi seperti hepatitis, kanker dan hasil reproduksi yang buruk, gangguan pendengaran, cedera muskuloskeletal, penyakit kardiovaskular, trauma akut cedera, dan kematian.

Perawat dalam melakukan perawatan pada pasien banyak melakukan aktivitas mengangkat, memindahkan, mendorong, atau menarik pasien. Selain itu perawat banyak melakukan aktivitas dalam posisi berdiri atau berjalan dalam jangka waktu yang cukup lama. 
Aktivitas yang dilakukan perawat dalam menangani pasien serta interaksi dengan lingkungan fisik berisiko terjadinya gangguan muskoloskeletal. Gangguan muskoloskeletal merupakan gangguan yang terjadi pada otot, tulang, tendon, pembuluh darah, sistem persyarafan, dan jaringan lunak lainnya.

Berdasarkan uraian dan data-data yang di kemukakan diatas penulis tertarik untuk melakukan penelitian dikarenakan yang menjadi permasalahannya masih rendahnya tingkat kesadaran terhadap risiko yang mengancam dirinya dan rendahnya tingkat kepatuhan perawat atau petugas medis dalam memperhatikan keselamatan dan kesehatan kerja (K3). Maka daripada itu, penulis mengangkat judul "Pelaksanaan Keselamatan dan Kesehatan Kerja Gangguan Muskoloskeletal Akibat Pekerjaan Pada Perawat”.

\section{Metode}

Kajian ini menggunakan metode kualitatif, metode kualitatif ini bersifat memberikan penjelasan dengan membuat analisis. Proses pengkajian ini lebih menggunakan landasan teori dengan mengumpulkan data, bereksplorasi bebas yang telah disimpulkan dari berbagai sumbersumber buku dan jurnal perencanaan keperawatan. Analisisis dibuat dengan berkaitan dengan keselamatan dan kesehatan kerja rumah sakit terhadap penyakit akibat kerja.

\section{Hasil}

Hasil dari literature review di dapatkan bahwa terdapat hubungan antara posisi tubuh saat bekerja dengan keluhan musculoskeletal. Gangguan muskoloskeletal merupakan hal yang merugikan jika terjadi pada petugas kesehatan. Hal ini memberikan dampak baik secara biologis, psikologis, sosial, dan organisasi.

Sebagian besar tenaga kesehatan merupakan tenaga keperawatan dan kebidanan. Perawat secara global merupakan tenaga kerja terbanyak dan memiliki peran yang unik dalam mencapai tujuan kesehatan bagi seluruh masyarakat melalui pemberian layanan keperawatan Oleh karena itu perawat harus benar-benar di terapkan dalam penggunaan APD di suatu rumah sakit dimana di 
dalamnya tenaga kesehatan melakukan pekerjaan dengan baik. Hal ini dilakukan karena perawat adalah faktor yang paling penting dalam suatu penggunaan APD.

Perawat dalam melaksanakan asuhan kepada pasien memiliki tugas yang bervariasi, antara lain melakukan tindakan mandiri seperti memenuhi kebutuhan Activity Daily Living (ADL) pasien, memandikan di tempat tidur, membantu mobilisasi pasien dengan cara mengangkat pasien mulai dari yang ringat sampai yang berat, melakukan resusitasi jantung paru, merawat luka dan lain-lain. Selain tindakan mandiri perawat juga mempunyai tugas yang sifatnya kolaboratif seperti memberikan obat melalui suntikan, memasang cateter dan lain-lain. Perawat dalam melakukan pekerjaannya tersebut banyak menggunakan gerakan membungkuk dan memutar tubuh, khususnya di sekitar tulang punggung bawah, mengangkat benda berat, dan mentransfer pasien merupakan faktor risiko terbesar terkena gangguan muskoloskletal.

Perawat yang mengalami gangguan muskoloskletal akan mengeluhkan ketidaknyamanan rasa nyeri, dan keterbatasan pergerakan sehingga memberikan batasan terhadap pemenuhan kebutuhan sehari-hari. Gangguan muskoloskeletal mengakibatkan rasa nyeri, sakit kronis, stres psikologis, dan keterbatasan pergerakan sehingga memberikan batasan terhadap pemenuhan kebutuhan sehari-hari.

\section{Pembahasan}

Kecelakaan kerja adalah kejadian yang tidak terduga dan tidak diharapkan. Oleh karena itu, diperlukan upaya pembinaan pelaksanaan keselamatan dan kesehatan kerja (K3) agar terhidar dari kecelakaan kerja. Perilaku tidak aman perawat saat bekerja tanpa menggunakan alat pelindung diri sesuai standar dapat mengakibatkan kecelakaan kerja dan menimbulkan penyakit akibat kerja.

Tindakan tidak aman (unsafe action) adalah tindakan yang dapat membahayakan pekerja itu sendiri maupun orang lain yang dapat menyebabkan terjadinya kecelakaan yang dapat disebabkan oleh berbagai hal seperti tidak memakai APD, tidak mengikuti prosedur kerja, tidak mengikuti peraturan keselamatan kerja dan bekerja tidak hati-hati, dimana dari setiap 300 tindakan tidak aman, akan terjadi 1 (satu) kali kecelakaan yang mengakibatkan kehilangan hari kerja. 
Alat pelindung diri (APD) merupakan suatu alat yang di pakai untuk melindungi diri atau tubuh terhadap bahaya-bahaya kecelakaan kerja (perwat), dimana secara teknis dapat mengurangi tingkat keparahan dari kecelakaan kerja yang terjadi pada perawat atau pasien. Alat pelindung diri ini hanya mengurangi jumlah kontak dengan bahaya yang dengan cara penempatan penghalang antara tenaga kerja dengan bahaya yang ada pada pasien dan bahkan sebaliknya.

Faktor pengalaman pada tugas yang sama dan lingkungan yang sudah dikenal dapat mempengaruhi perawat tersebut berperilaku tidak aman karena menyenangkan, nyaman dan menghemat waktu dan perilaku ini cenderung berulang. Hal ini membuktikan bahwa perawat yang mempunyai pengalaman kerja lebih lama cenderung kurang berhati-hati karena merasa bisa menguasai semua jenis pekerjaan sehingga sering bertindak sembrono dan tidak memperhatikan prinsip dasar keselamatan dalam bekerja.

Rumah sakit dapat mengurangi jumlah kejadian tertusuk benda tajam dengan meningkatkan sikap perawat dimana sikap sangat berhubungan dengan perilaku. Sikap yang pro aktif untuk mengaplikasikan ilmu baru tentang pelaksanaan keselamatan dan kesehatan kerja. Semakin pro aktif mengaplikasikan ilmu baru maka akan semakin bersikap positif tentang pelaksanaan K3 sehingga akan mengurangi kejadian kecelakaan kerja. Pelatihan keselamatan dan kesehatan kerja sangat penting mengingat kebanyakan kecelakaan terjadi pada pekerja yang belum terbiasa bekerja secara selamat. Penyebabnya adalah ketidaktahuan tentang bahaya atau cara mencegahnya meskipun tahu tentang adanya suatu resiko.

Kemudian perlu adanya pemanfaatan media sosialisasi oleh bagian Komite K3RS yang berisi tentang prosedur K3 terutama untuk pencegahan kejadian kecelakaan kerja. Untuk itu maka diperlukan media sosialisasi yang dapat di akses dengan mudah oleh perawat tentang informasi pelaksanaan K3, sehingga efisien dan efektif dalam menyampaikan promosi K3. Media sosial tersebut dapat mengakomodir kebutuhan informasi, ilmu baru, praktik terbaik tentang penanggulangan kecelakaan kerja yang dikelola oleh Komite K3RS.

Faktor predisposing (pencetus) (pengetahuan, sikap, kepercayaan dan nilai) memiliki hubungan yang sangat berpengaruh terhadap keselamatan dan kesehatan kerja pada perawat dalam penanganan pasien. Kepercayaan memiliki nilai yang sangat baik dan memiliki pengaruh yang sangat baik terhadap perilaku seseorang, Sedangkan nilai untuk pengetahuan adalah yang paling 
rendah. Kepercayaan inilah yang mendasari perilaku perawat bahwa K3 sangat penting dan sangat berarti untuk dirinya, sehingga mereka berperilaku yang baik terhadap pelaksanaan K3RS.

Faktor reinforcing (pendorong) (petugas yang menjadi contoh) pada perawat terhadap K3RS. Secara kesahihan dan keandalan instrument sebagai alat ukur sudah memenuhi syarat namun sebagai veriabel yang mempengaruhi perilaku keselamatan dan kesehatan kerja tidak berpengaruh, hal ini mungkin terjadi karena petugas yang bertanggung jawab kurang melaksanakan tugas K3 sebagai akibat tugas rangkap, maka bila telah dilaksanakan dengan kesadaran sendiri faktor pendorong kurang berarti, sehingga tidak berpengaruh terhadap keselamatan dan kesehatan kerja.

Faktor enabling (fasilitas keamanan dan keselamatan, hukum/aturan) pada perawat terhadap K3RS. Nilai yang paling tinggi pada faktor enabling berada pada komponen hukum/aturan karena pada prinsipnya perilaku seseorang dipengaruhi oleh aturan yang ada di lingkungannya. Kebiasaan dalam menaati aturan ini menjadi kebiasaan yang baik sehingga ia tidak akan melanggar aturan karena kebiasaan disiplin dan sanksi dari aturan tersebut.

Faktor core, and care (hubungan interpersonal dan kepedulian) berpengaruh terhadap keselamatan dan kesehatan kerja pada perawat dalam penanganan pasien.

Kelelahan kerja adalah keadaan dimana tubuh mengalami penurunan daya tahan kerja yang di akibatkan adanya beban kerja yang diterima seseorang pada saat bekerja. Perawat dapat melakukan kesalahan dalam pelayanan karena kelelahan yang dirasakan. Kelelahan kerja akan menurunkan kinerja, menurunkan kapasitas kerja dan ketahanan kerja yang ditandai oleh sensasi lelah, motivasi menurun, aktivitas menurun.

Ranupendoyo dan Saud (2005), yang menyebutkan bahwa semakin lama seseorang bekerja maka akan semakin berpengalaman orang tersebut sehingga kecakapan kerjanya semakin baik sehingga menurunkan risiko terjadinya keluhan muskuloskeletal. Posisi tubuh yang tidak ergonomis saat bekerja menyebabkan posisi bagian-bagian tubuh bergerak menjauhi posisi alamiah, misalnya pergerakan tangan mengangkat, punggung terlalu membungkuk dan kepala terangkat.

Jenis kecelakaan kerja paling banyak yang terjadi pada perawat adalah gangguan muskuloskeletal. Perawat yang mengalami gangguan muskoloskletal akan mengeluhkan 
ketidaknyamanan rasa nyeri, dan keterbatasan pergerakan sehingga memberikan batasan terhadap pemenuhan kebutuhan sehari-hari (Hindawi, 2017). Gangguan ini didapat karena perawat bekerja pada posisi tubuh yang sama dalam waktu yang lama seperti pada saat perawat memasang infus, memandikan pasien, mengangkat pasien yang gemuk, memindahkan pasien dari/ke kursi roda/brankar, membuang urine, dan lain-lain.

Terdapat tiga posisi tubuh saat bekerja yaitu posisi tubuh saat duduk, berdiri, dan membungkuk. posisi tubuh yang paling sering digunakan saat bekerja adalah posisi tubuh berdiri dan membungkuk yang dapat dilihat pada empat tindakan keperawatan yaitu rawat luka, menjahit luka, pemasangan infus, dan pengambilan darah. Tindakan yang dapat dilakukan oleh perawat dalam hal ini adalah dengan melakukan pengaturan tinggi tempat tidur sehingga posisi tubuh sejajar dengan area permukaan tempat kerja.

Gangguan muskuloskletal memberikan dampak terhadap lingkungan kerja. Dampak yang dirasakan adalah berupa kurang fokusnya perawat serta adanya hambatan terhadap pemanfaatan berbagai sumber daya kerja yang ada. sehingga hal ini mengakibatkan penggunaan waktu optimum kerja terhadap berbagai aktivitas intervensi yang dilakukan lebih panjang. Hal ini dapat disimpulkan cedera muskuloskletal membuang waktu kerja efektif perawat.

Cedera muskoloskletal akan memberikan dampak secara biologis pada perawat berupa penurunan massa otot, penurunan efisiensi penggunaan otot dan penurunan ketahanan tulang intervetebra. Hal ini akan menggiring penurunan produktivitas kerja perawat dikarenakan penurunan daya tahan dan perburukan mobilitas. Ketika dua hal tersebut terjadi perawat akan kehilangan kemampuan untuk melakukan pemindahan, pengangkatan, dan pedorongan pasien sehingga menurunkan fungsi perawatan langsung terhadap pasien (Watson, 2008, Vinstrup, 2017).

Gangguan muskoloskeletal mengakibatkan rasa nyeri, sakit kronis, stres psikologis, dan keterbatasan pergerakan sehingga memberikan batasan terhadap pemenuhan kebutuhan seharihari. Tidak terpenuhinya kebutuhan dasar sehari-hari memunculkan keluhan fisik yang menurunkan kualitas hidup penderita.

Intervensi ergonomis merupakan salah satu intervensi yang diusulkan dalam pencegahan dan pengobatan gangguan muskuloskeletal akibat pekerjaan. Intervensi ergonomi dalam 
pencegahan cedera muskuloskeletal memiliki hasil yang menjanjikan. Intervensi ergonomi bertujuan mengetahui penyebab dan faktor yang berkontribusi terhadap cedera muskuloskeletal.

Rumah sakit sebagai insitusi harus mulai memberikan perhatian serius dalam menangani permasalahan ini untuk meningkatkan angka produktivitas petugas kesehatan dan mengurangi pengeluaran pembiayaan sehingga dapat terus berkompetisi dalam peningkatan kualitas layanan kesehatan pada masyarakat.

\section{Kesimpulan}

Bahaya pekerjaan mengacu pada aktivitas tempat kerja yang memiliki potensi menyebabkan / meningkatkan risiko cedera atau gangguan kesehatan. Perawat sebagai tenaga kesehatan yang dapat menimbulkan infeksi yang berdampak keparahan bahkan sampai meninggal. Pentingnya pengetahuan keselamatan dan kesehatan kerja oleh perawat di rumah sakit guna untuk meningkatkan mutu pelayanan serta keselamatan pada tenaga medis. Gangguan muskuloskeletal ini didapat karena perawat bekerja pada posisi tubuh yang sama dalam waktu yang lama.

\section{Daftar Pustaka}

Ismail, F., \& Supriyadi, S. (2020). HUBUNGAN STRES KERJA DENGAN KELELAHAN KRONIS PADA PERAWAT DI RUANG RAWAT INAP RSUD WONOSARI. JURNAL KEPERAWATAN AKPER YKY YOGYAKARTA, 12(1), 9-18.

Istih, S. M. P., Wiyono, J., \& Candrawati, E. (2017). Hubungan Unsafe Action dengan Kecelakaan Kerja Pada Perawat di Rumah Sakit Panti Waluya Malang. Nursing News: Jurnal Ilmiah Keperawatan, 2(2).

PI, S. M., Wiyono, J., \& Candrawati, E. (2017). Kejadian kecelakaan kerja perawat berdasarkan tindakan tidak aman. Care: Jurnal Ilmiah Ilmu Kesehatan, 3(2), 9-17.

Putri, S., Santoso, S., \& Rahayu, E. P. (2018). Pelaksanaan keselamatan dan kesehatan kerja terhadap Kejadian Kecelakaan Kerja Perawat Rumah Sakit. Jurnal Endurance, 3(2), 271-277.

Putri, Z. M., Khairina, I., \& Refnandes, R. (2020). Gambaran Gangguan Muskoloskeletal pada Perawat. Jurnal Ilmiah Universitas Batanghari Jambi, 20(2), 399-401. 
Putri, Z. M., Murni, D., Maisa, E. A., Khairina, I., \& Muthmainnah, M. (2019). DAMPAK GANGGUAN MUSKOLOSKELETAL AKIBAT PEKERJAAN PADA PERAWAT di RSI SITI RAHMAH PADANG TAHUN 2019. In PROSIDING SEMINAR KESEHATAN PERINTIS (Vol. 2, No. 1, pp. 133-133).

Shinde, M., Sadare, S., \& Potdar, N. (2016). Awareness of occupational health hazards among staff nurses. Int J Sci Res, 5(12), 2319-7064.

Simamora, R. H. (2017). A strengthening of role of health cadres in BTA-Positive Tuberculosis (TB) case invention through education with module development and video approaches in Medan Padang bulan Comunity Health Center, North Sumatera Indonesia. International Journal of Applied Engineering Research, 12(20), 10026-10035.

Simamora, R. H., \& Saragih, E. (2019). Penyuluhan kesehatan terhadap masyarakat: Perawatan penderita asam urat dengan media audiovisual. JPPM (Jurnal Pendidikan dan Pemberdayaan Masyarakat), 6(1), 24-31.

Sitorus, E. D., \& Sunengsih, A. (2016). TINGKAT KEPATUHAN PERAWAT MENGENAI SOP DALAM PENGGUNAAN APD DI RUANG RAWAT BEDAH LT. 12 BLOK. D RSUD KOJA JAKARTA UTARA TAHUN 2016. Jurnal Akademi Keperawatan Husada Karya Jaya, 2(2).

Sudarmo, S., Helmi, Z. N., \& Marlinae, L. (2017). Faktor Yang Mempengaruhi Perilaku Terhadap Kepatuhan Penggunaan Alat Pelindung Diri (Apd) Untuk Pencegahan Penyakit Akibat Kerja. Jurnal Berkala Kesehatan, 1(2), 88-95.

Sulasmi, N. P. W., Mustriwati, K. A., \& Atmaja, I. K. W. HUBUNGAN MASA KERJA DAN POSISI TUBUH SAAT BEKERJA DENGAN KELUHAN MUSKULOSKELETAL PADA PERAWAT.

Tukatman, S., \& Purwaningsih, N. (2015). Analisis Keselamatan dan Kesehatan Kerja Perawat dalam Penanganan Pasien di Rumah Sakit Benyamin Guluh Kabupaten Kolaka. J Ners, 10(2), 343-7. 